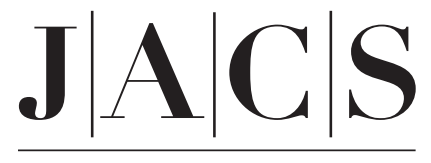

A R T I C L E S

Published on Web 05/17/2005

\title{
Infrared Fingerprint Spectroscopy and Theoretical Studies of Potassium lon Tagged Amino Acids and Peptides in the Gas Phase
}

\author{
Nick C. Polfer, ${ }^{*, \dagger}$ Béla Paizs, ${ }^{*, \neq}$ Lavina C. Snoek, ${ }^{\S}$ Isabelle Compagnon, ${ }^{\dagger}$ \\ Sándor Suhai,, Gerard Meijer," Gert von Helden," and Jos Oomens ${ }^{\dagger}$ \\ Contribution from the FOM-Institute for Plasmaphysics Rijnhuizen, Edisonbaan 14, NL-3439 \\ MN Nieuwegein, The Netherlands, German Cancer Research Center, Im Neuenheimer Feld 580, \\ D-69120 Heidelberg, Germany, Chemistry Department, Physical and Theoretical Chemistry \\ Laboratory, Oxford University, Oxford OX1 3QZ, U.K., and Fritz-Haber-Institut der \\ Max-Planck-Gesellschaft, Faradayweg 4-6, D-14195 Berlin, Germany
}

Received February 9, 2005; E-mail: polfer@rijnh.nl; B.Paizs@dkfz.de

\begin{abstract}
Infrared multiple-photon dissociation spectroscopy is effected on the $\mathrm{K}^{+}$tagged aromatic amino acids tyrosine and phenylalanine, as well as the $\mathrm{K}^{+}$tagged peptides bradykinin fragment 1-5 and [Leu]enkephalin. The fingerprint $\left(800-1800 \mathrm{~cm}^{-1}\right)$ infrared spectra of these species are compared to densityfunctional theory (DFT) calculated spectra to determine whether the complex is in the charge solvation (CS) or salt bridge (SB) (i.e. zwitterionic) configuration. For the aromatic amino acids the CS structure is favored and the tridentate $\mathrm{N} / \mathrm{O} /$ ring structure is found to be the preferred binding geometry for $\mathrm{K}^{+}$. The experimental and theoretical evidence for bradykinin fragment 1-5 tagged with $\mathrm{K}^{+}$suggests that the $\mathrm{SB}$ structure is favored; the calculations indicate a head-to-tail looped structure stabilized by a salt bridge between the protonated guanidine group and the deprotonated $\mathrm{C}$-terminus, which allows $\mathrm{K}^{+}$to sit in a binding pocket with five $\mathrm{C}=\mathrm{O}$ electrostatic interactions. For $\mathrm{K}^{+}$tagged [Leu]-enkephalin the spectroscopic evidence is not as clear. While the calculations clearly favor a CS structure and the observation of a weak carboxylic acid $\mathrm{C}=\mathrm{O}$ stretching band in the infrared spectrum matches this finding, the prominence of a band at $1600 \mathrm{~cm}^{-1}$ renders the analysis more ambiguous, and hence the presence of some salt bridge ions cannot be excluded. Another striking feature in the [Leu]-enkephalin spectrum is the high infrared activity of the tyrosine side-chain modes, which can be clearly identified from comparison to the $[\mathrm{Tyr}+\mathrm{K}]^{+}$ experimental spectrum, but which is not reproduced by the DFT calculations.
\end{abstract}

\section{Introduction}

Noncovalent interactions, such as hydrogen bonding, salt bridge interactions, the hydrophobic effect, and cation $-\pi$ interactions, determine the higher order (secondary, tertiary, and quaternary) structures of proteins. The noncovalent interaction that regulates the biological function of a protein depends from case to case: salt bridging is thought to play a crucial role in the assembly of some protein multimers ${ }^{1}$ and enzyme-receptor recognition, ${ }^{2}$ whereas cation $-\pi$ interactions ${ }^{3,4}$ are believed to be responsible for the ion selectivity of potassium channels. ${ }^{5}$ Given the very large number of degrees of freedom of a biological macromolecule and the fact that many noncovalent interactions may be counteracting, it is inherently difficult to solve the "protein folding problem". ${ }^{6,7}$ The alkali metals sodium

\footnotetext{
FOM-Institute for Plasmaphysics Rijnhuizen.

German Cancer Research Center.

$\S$ Oxford University.

" Fritz-Haber-Institut der Max-Planck-Gesellschaft.

(1) Yu, B. M.; Paroutis, P.; Davidson, A. R.; Howell, P. L. J. Biol. Chem. 2004, 279, 40972-40979.

(2) de Vos, A. M.; Ultsch, M.; Kossiakoff, A. A. Science 1992, 255, 306312 .

(3) Dougherty, D. A. Science 1996, 271, 163-168.

(4) Ma, J. C.; Dougherty, D. A. Chem. Rev. 1997, 97, 1303-1324.

(5) Kumpf, R. A.; Dougherty, D. A. Science 1993, 261, 1708-1710.
}

10.1021/ja050858u CCC: $\$ 30.25$ @ 2005 American Chemical Society and potassium are among the most abundant and important metals in biological systems. ${ }^{8,9}$ Alkali metal binding to proteins can affect the biological function: the binding of a sodium or potassium cation to the active site of the enzyme dialkylglycine decarboxylase significantly changes the geometry of the active site of the protein, thus explaining the dependence of activity on the presence of potassium. ${ }^{10}$ More fundamental knowledge is required to understand how the binding of alkali metals to peptides and proteins affects their structure.

Computational modeling of these systems relies on a detailed understanding of the individual noncovalent driving forces. Many of these interactions can only be accurately modeled by high-level theory calculations, and hence the size of model systems is restricted. In this light it is essential to simplify the problem by studying smaller systems in the absence of solvent (i.e. in the gas phase). The binding of alkali metals to amino

(6) Koehl, P.; Levitt, M. Nature Struct. Biol. 1999, 6, 108-111.

(7) Jones, D. T.; Taylort, W. R.; Thorton, J. M. Nature 1992, 358, 86-89.

(8) da Silva, J. J. R. F.; Williams, R. J. P. The Biological Chemistry of the Elements: The Inorganic Chemistry of Life; Oxford University Press: New York, 1991.

(9) Wilkins, P. C.; Wilkins, R. G. Inorganic Chemistry in Biology; Oxford University Press: New York, 1997.

(10) Toney, M. D.; Hohenester, E.; Cowan, S. W.; Jansonius, J. N. Science 1993, 261, 756-759. 
acids has been the subject of numerous computational studies, mainly at the density-functional theory (DFT) level. ${ }^{11-15}$ While most amino acids are known to be in the zwitterionic (dipolar) state in solution (at biological $\mathrm{pH}$ ), many computational studies have tried to shed light on whether amino acids can exist as zwitterions in the gas-phase intrinsically ${ }^{16,17}$ and how water molecules can stabilize the zwitterionic structure. ${ }^{18-20}$ Cations, such as alkali metals, can favor the zwitterionic structure by stabilizing the negative charge on the carboxylate group. ${ }^{14,21-23}$

The modeled structures need to be compared against experimental data in order to validate the models. Soft ionization techniques such as electrospray ionization (ESI) ${ }^{24}$ allow large biomolecules and even noncovalently bound complexes to be transferred intact into the gas phase, thereby significantly extending the species that can be studied by mass spectrometric techniques. ${ }^{25}$ Gas-phase experiments permit an accurate manipulation of the ions, thereby allowing a wealth of valuable physical data on the systems under investigation to be gained. Techniques that have been applied to investigate the existence of zwitterions in the gas phase for amino acids and small peptides include H/D exchange, ${ }^{26-29}$ ion mobility, ${ }^{22,30}$ blackbody infrared radiative dissociation (BIRD), ${ }^{31,32}$ high-pressure mass spectrometric studies, ${ }^{33}$ the kinetic method, ${ }^{34-36}$ threshold collision-induced dissociation, ${ }^{13,15}$ ligand exchange equilibri$\mathrm{um}^{37,38}$ and infrared multiphoton dissociation (IRMPD). ${ }^{39}$

The results of some of these studies have been contradictory, and hence there is ongoing debate about the existence of

(11) Dunbar, R. C. J. Phys. Chem. A 2000, 104, 8067-8074.

(12) Siu, F. M.; Ma, N. L.; Tsang, C. W. J. Am. Chem. Soc. 2001, 123, 33973398.

(13) Moision, R. M.; Armentrout, P. B. J. Phys. Chem. A 2002, 106, 1035010362.

(14) Marino, T.; Russo, N.; Toscano, M. J. Phys. Chem. B 2003, 107, 25882594.

(15) Ruan, C.; Rodgers, M. T. J. Am. Chem. Soc. 2004, 126, 14600-14610.

(16) Skurski, P.; Gutowski, M.; Barrios, R.; Simons, J. Chem. Phys. Lett. 2001, 337, 143-150.

(17) Rak, J.; Skurski, P.; Simons, J.; Gutowski, M. J. Am. Chem. Soc. 2001, 123, 11695-11707.

(18) Jensen, J. H.; Gordon, M. S. J. Am. Chem. Soc. 1995, 117, 8159-8170

(19) Ding, Y. B.; Krogh-Jesperson, K. Comput. Chem. 1996, 17, 338-349.

(20) Tajkhorshid, E.; Jalkanen, K. J.; Suhai, S. J. Phys. Chem. B 1998, 102, 5899-5913.

(21) Hoyau, S.; Ohanessian, G. Chem.-Eur. J. 1998, 4, 1561-1569.

(22) Wyttenbach, T.; Witt, M.; Bowers, M. T. J. Am. Chem. Soc. 2000, 122, $3458-3464$

(23) Kapota, C.; Lemaire, J.; Maitre, P.; Ohanessian, G. J. Am. Chem. Soc. 2004, $126,1836-1842$

(24) Fenn, J. B.; Mann, M.; Meng, C. K.; Wong, S. F.; Whitehouse, C. M. Science 1989, 246, 64-71.

(25) Schalley, C. A. Int. J. Mass Spectrom. 2000, 194, 11-39.

(26) Campbell, S.; Rodgers, M. T.; Marzluff, E. M.; Beauchamp, J. L. J. Am. Chem. Soc. 1995, 117, 12840-12854

(27) Freitas, M. A.; Marshall, A. G. Int. J. Mass Spectrom. 1999, 182, 221231

(28) Geller, O.; Lifshitz, C. J. Phys. Chem. A 2003, 107, 5654-5659

(29) Wyttenbach, T.; Paizs, B.; Barran, P.; Breci, L. A.; Liu, D.; Suhai, S.; Wysocki, V. H.; Bowers, M. T. J. Am. Chem. Soc. 2003, 123, 1376813775.

(30) Wyttenbach, T.; Witt, M.; Bowers, M. T. Int. J. Mass Spectrom. 1999, $182 / 183,243-252$.

(31) Price, W. D.; Jockusch, R. A.; Williams, E. R. J. Am. Chem. Soc. 1998 , 120, 3474-3484

(32) Jockusch, R. A.; Lemoff, A. S.; Williams, E. R. J. Am. Chem. Soc. 2001, $123,12255-12265$.

(33) Hoyau, S.; Norrman, K.; McMahou, T. B.; Ohanessian, G. J. Am. Chem. Soc. 1999, 121, 8864-8875.

(34) Bojesen, G.; Breindahl, T.; Anderson, U. N. Org. Mass Spectrom. 1993, $28,1448-1452$

(35) Ryzhov, V.; Dunbar, R. C.; Cerda, B. A.; Wesdemiotis, C. J. Am. Soc. Mass Spectrom. 2000, 11, 1037-1046.

(36) Kish, M. M.; Ohanessian, G.; Wesdemiotis, C. Int. J. Mass Spectrom. 2003, $227,509-524$.

(37) Gapeev, A.; Dunbar, R. C. J. Am. Chem. Soc. 2001, 123, 8360-8365.

(38) Gapeev, A.; Dunbar, R. C. Int. J. Mass Spectrom. 2003, 228, 825-839.

(39) Schaefer, M.; Schmuck, C.; Geiger, L.; Chalmers, M. J.; Hendrickson, C. L.; Marshall, A. G. Int. J. Mass Spectrom. 2004, 237, 33-45. zwitterions in the gas phase for some of the studied systems. Nevertheless, on the basis of these fundamental studies and theoretical calculations, it is widely accepted that an alkali metal can engage in $\pi$-bonding to the aromatic amino acid side chains of phenylalanine, tryptophan, or tyrosine with a predicted binding strength of $\sim 100 \mathrm{~kJ} \mathrm{~mol}^{-135}$ and that when an amino acid is in the zwitterionic form, the alkali metal is believed to bind to the negatively charged carboxylate group, forming a salt bridge (SB) structure with a binding strength of $\sim 150 \mathrm{~kJ}$ $\mathrm{mol}^{-1} \cdot 14$

More recently infrared spectroscopic techniques have been employed to yield important conformational information on amino acids and di- and tripeptides in the gas phase. ${ }^{23,40-45}$ Infrared spectroscopy gives additional information of the gasphase structure of biomolecules to for example ion mobility or $\mathrm{H} / \mathrm{D}$ exchange and is a direct probe of the presence of particular chemical groups. A popular infrared spectroscopic technique involves a two-photon scheme (ion dip or fluorescence dip spectroscopy) on neutral molecules in a molecular beam expansion. Relatively little infrared spectroscopic work has so far been done on biological ions in the gas phase: Infrared spectroscopy of sodium-bound amino acids glycine and proline has allowed an assignment of the CS and SB structures; ${ }^{23}$ the structures of $\mathrm{H}^{+}$-bound amino acids could be elucidated; ${ }^{46}$ the protonation sites of the dialanine ${ }^{45}$ and Ala-His ${ }^{47}$ peptides could be determined on the basis of their infrared spectra, and $\mathrm{Na}^{+}$ and $\mathrm{K}^{+}$binding to benzene has been studied. ${ }^{41}$ Metal-containing complexes are also of interest due to their role as catalytic sites in proteins; these complexes are inherently ionic due to the charge on the metal cation and thus infrared spectroscopy of ions is becoming increasingly important. Due to the Coulombic repulsion of ions direct absorption spectroscopy is not feasible, and hence "action" spectroscopy needs to be employed, where light absorption causes a change in the species under study. In infrared multiple-photon dissociation (IR-MPD) ${ }^{48}$ the molecule is "heated" sufficiently to induce fragmentation and hence a change in the mass of the species. The multiple photon absorption process is mediated by intramolecular vibrational redistribution (IVR). ${ }^{49,50}$ To use IR-MPD as a spectroscopic tool, one needs an intense and continuously tunable laser source. Free electron lasers (FEL) have recently been shown to be very adequate for this task. ${ }^{23,51-54}$

(40) Chapo, C. J.; Paul, J. B.; Provencal, R. A.; Roth, K.; Saykally, R. J. J. Am. Chem. Soc. 1998, 120, 12956-12957.

(41) Cabarcos, O. M.; Weinheimer, C. J.; Lisy, J. M. J. Chem. Phys. 1999 $110,8429-8435$

(42) Bakker, J. M.; McAleese, L. M.; Meijer, G.; von Helden, G. Phys. Rev. Lett. 2003, 91, 203003.

(43) Special issue "Bioactive Molecules in the Gas Phase". Phys. Chem. Chem. Phys. 2004, 6, 2543-2890.

(44) Dian, B. C.; Clarkson, J. R.; Zwier, T. S. Science 2004, 303, 1169-1173.

(45) Lucas, B.; Gregoire, G.; Lemaire, J.; Maitre, P.; Ortega, J.-M.; Rupenyan, A.; Reimann, B.; Schermann, J.-P.; Desfrancois, C. Phys. Chem. Chem Phys. 2004, 6, 2659-2663.

(46) Oh, H.; Lin, C.; Hwang, H. Y. Zhai, H; Breuker, K. Zabrouskov, V. Carpenter, B. K.; McLafferty, F. W. J. Am. Chem. Soc. 2005, 127, 40764083.

(47) Lucas, B.; Gregoire, G.; Lemaire, J.; Maitre, P.; Glotin, F.; Schermann, J.-P.; Desfrancois, C. Int. J. Mass Spectrom. 2005, 243, 97-105.

(48) Bagratashvili, V. N.; Letokov, V. S.; Makarov, A. A.; Ryabov, E. A. Multiple Photon Infrared Laser Photophysics and Photochemistry; Harwood: Chur, Switzerland, 1985.

(49) Grant, E. R.; Schulz, P. A.; Sudbo, A. S.; Shen, Y. R.; Lee, Y. T. Phys. Rev. Lett. 1978, 40, 115-118.

(50) von Helden, G.; Hollemann, I.; Meijer, G.; Sartakov, B. Opt. Express 1999 $4,46-52$.

(51) Oomens, J.; van Roij, A. J. A.; Meijer, G.; von Helden, G. Astrophys. J. 2000, 542, 404-410. 
So far, no mid-infrared spectroscopy has been demonstrated on larger metal-bound peptides. Here, we present the application of infrared photofragment spectroscopy to the amino acids tyrosine and phenylalanine, and two pentapeptides, bradykinin fragment 1-5 and [Leu]-enkephalin, all bound to a potassium cation. Variants of the peptide bradykinin have been the subject of a number of studies relating to its zwitterionic structure. ${ }^{27,55,56}$ While bradykinin fragment 1-5 possesses a high gas-phase basicity arginine group and might hence be expected to form a $\mathrm{SB}$ structure with $\mathrm{K}^{+}$in the gas phase, [Leu]-enkephalin has no such basic group and would thus likely be in a CS conformation. Hence these peptides are good candidates for the experimental and theoretical elucidation of CS and SB structures in the gas phase. The potential energy surfaces (PESs) of these species have been explored utilizing molecular dynamics simulations and quantum chemical calculations to identify the energetically most preferred charge-solvated and salt-bridge conformers for which frequency calculations have been carried out using the B3LYP density functional theory (DFT) method. High-level theory calculations of systems as large as pentapeptides are challenging due to the high number of degrees of freedom and have only recently been attempted ${ }^{29,57-60}$ and this is the first study of alkali metal bound pentapeptides.

\section{Experimental and Computational Section}

The infrared multiple-photon dissociation spectroscopy measurements have been performed at the FOM-Institute for Plasmaphysics "Rijnhuizen" in Nieuwegein (Netherlands) using the Free Electron Laser for Infrared eXperiments (FELIX) facility. The molecular dynamics simulations and the quantum chemical calculations were carried out at the German Cancer Research Center in Heidelberg (Germany). Both the experimental and theoretical strategies are briefly described below.

(1) Mass Spectrometry Setup. All experiments are carried out in a laboratory-built Fourier transform ion cyclotron resonance (FT-ICR) mass spectrometer, ${ }^{61}$ which has recently been fitted with an external commercial electrospray ionization (ESI) source source (Z-Spray, Micromass U.K. Ltd.) and an octopole ion guide. The amino acids phenylalanine and tyrosine (Sigma-Aldrich) are made up in a 0.75: $0.25 \mathrm{MeOH}: \mathrm{H}_{2} \mathrm{O}$ solution at a concentration of $1 \mathrm{mM}$ with added $\mathrm{KCl}$ also at a concentration of $1 \mathrm{mM}$. The peptides bradykinin fragment 1-5 (Arg-Pro-Pro-Gly-Phe; Sigma-Aldrich) and [Leu]-enkephalin (TyrGly-Gly-Phe-Leu; Bachem) are made up at a concentration of $60 \mu \mathrm{M}$ with identical solvent conditions and $\mathrm{KCl}$ concentration as for the amino acids. The gas-phase complexes of amino acids/peptides tagged with $\mathrm{K}^{+}$are produced with ESI; the ions travel through a quadrupole bender (ABB Extrel) into the octopole, which enables them to enter the magnetic field lines. Trapping in the ICR cell is effected by pulsing a

(52) Lemaire, J.; Boissel, P.; Heninger, M.; Mauclaire, G.; Bellec, G.; Mestdagh, H.; Simon, A.; Caer, S. L.; Ortega, J.-M.; Glotin, F.; Maitre, P. Phys. Rev. Lett. 2002, 89, 273002.

(53) Moore, D. T.; Oomens, J.; Eyler, J. R.; Meijer, G.; von Helden, G.; Ridge, D. P. J. Am. Chem. Soc. 2004, 126, 14726-14727.

(54) Oomens, J.; Moore, D. T.; von Helden, G.; Meijer, G.; Dunbar, R. C. J. Am. Chem. Soc. 2004, 26, 724-725.

(55) Wyttenbach, T.; von Helden, G.; Bowers, M. T. J. Am. Chem. Soc. 1996 $118,8355-8364$

(56) Strittmatter, E. F.; Williams, E. R. J. Phys. Chem. A 2000, 104, 60696076 .

(57) Kubelka, J.; Gangani, R. A.; Silva, D.; Keiderling, T. A. J. Am. Chem. Soc. 2002, 124, 5325-5332.

(58) Wieczorek, R.; Dannenberg, J. J. J. Am. Chem. Soc. 2003, 125, 81248129 .

(59) Watson, T. M.; Hirst, J. D. Phys. Chem. Chem. Phys. 2004, 6, 25802587.

(60) Paizs, B.; Suhai, S. J. Am. Soc. Mass Spectrom. 2004, 15, 103-113.

(61) Valle, J. J.; Eyler, J. R.; Oomens, J.; Moore, D. T.; van der Meer, A. F. G.; von Helden, G.; Meijer, G.; Hendrickson, C. L.; Marshall, A. G.; Blakney, G. T. Rev. Sci. Instrum. 2005, 76, 23103.
He gas pulse which collisionally relaxes the translational energy of the ions $(\sim 30 \mathrm{eV})$. The ions are left to cool by infrared emission for $1 \mathrm{~s}$ prior to stored waveform inverse Fourier transform (SWIFT) ${ }^{62}$ mass isolation. The spectra are linearly corrected for fluctuations in the laser power, although a more complicated dependence of the IR-MPD yield on laser power is probable. ${ }^{63,64}$

(2) Infrared Experiments. The $\mathrm{K}^{+}$cation tagged biomolecules are irradiated with 40 macropulses from FELIX. FELIX produces macropulses ( $5 \mu$ s in length) of high-intensity $(\sim 60 \mathrm{~mJ})$ infrared light over a very broad tuning range $\left(5-250 \mu \mathrm{m}, 2000-40 \mathrm{~cm}^{-1}\right)$ at a repetition rate of $5 \mathrm{~Hz}$. The bandwidth of the radiation is controllable and is set to about $0.8 \%$ of the central wavelength (i.e. $8 \mathrm{~cm}^{-1} \mathrm{fwhm}$ at 1000 $\mathrm{cm}^{-1}$ ). A macropulse consists of a train of picosecond long micropulses spaced by $1 \mathrm{~ns}$. Optical access of FELIX is provided by a ZnSe window on the rear side of the mass spectrometer and reflective optics that focus $(\mathrm{FL}=15 \mathrm{~cm})$ the laser beam in the center of the ICR cell. In IR-MPD resonant absorption of light causes bond cleavage in the ion of interest. For $\mathrm{K}^{+}$tagged biomolecules the lowest barrier dissociation channel is the desorption ("boiling off") of $\mathrm{K}^{+}$. Monitoring the appearance of $\mathrm{K}^{+}$as a function of wavelength and normalizing it with respect to the total ion population yields a background-free infrared spectrum of the species.

(3) Computational Details. A recently developed conformational search engine ${ }^{60,65-69}$ devised originally to deal with protonated peptides was modified and subsequently used to scan the PES of the $\mathrm{K}^{+}$tagged amino acids and peptides. These calculations started with molecular dynamics simulations on CS and SB species of the above ions using the Insight II program (Biosym Technologies, San Diego, CA) in conjunction with the AMBER force field. ${ }^{70}$ During the dynamics calculations we have used simulated annealing techniques to produce candidate structures for further refinement applying full geometry optimization using the AMBER force field. The optimized structures were then analyzed by a conformer family search program developed at Heidelberg. This program is able to group optimized structures into families for which the most important characteristic torsion angles of the molecule are similar and select structures with specific cation $-\pi$ interactions, etc. The most stable species in the families were then fully optimized at the HF/3-21G, B3LYP/6-31G(d), and finally at the B3LYP/ 6-31+G(d,p) levels, where the conformer families were regenerated at each level.

For the energetically most preferred structures we have performed frequency calculations at the B3LYP/6-31G(d) level of theory. Relative energies are calculated by comparing the B3LYP/6-31+G(d,p) total energies corrected for zero-point vibrational energy (ZPE) determined at the B3LYP/6-31G(d) level to that of the global minimum of a given ion. Our experiences with respect to the applied theoretical levels indicate that even $\mathrm{HF} / 3-21 \mathrm{G}$ performs reasonably well for the investigated ions, providing good approximation to geometry and qualitatively indicative relative energies; we have found that the energetic ranking of the various candidate structures calculated at the HF/3-21G level is rather similar to that determined at the B3LYP/6-31G(d) and B3LYP/6-31+G(d,p) levels. These facts suggest that the PESs of the

(62) Marshall, A. G.; Wang, T. C.; Ricca, T. L. J. Am. Chem. Soc. 1985, 107, 7893-7897.

(63) Oomens, J.; Sartakov, B. G.; Tielens, A. G. G. M.; Meijer, G.; von Helden, G. Astrophys. J. 2001, 560, L99-L103.

(64) Oomens, J.; Tielens, A. G. G. M.; Sartakov, B. G.; von Helden, G.; Meijer, G. Astrophys. J. 2003, 591, 968-985.

(65) Paizs, B.; Lendvay, G.; Vekey, K.; Suhai, S. Rapid Commun. Mass Spectrom. 1999, 13, 525-533.

(66) Csonka, I. P.; Paizs, B.; Lendvay, G.; Suhai, S. Rapid Commun. Mass Spectrom. 2000, 14, 417-431.

(67) Paizs, B.; Suhai, S. Rapid Commun. Mass Spectrom. 2001, 15, 23072323

(68) Paizs, B.; Suhai, S.; Hargittai, B.; Hruby, V. J.; Somogyi, A. Int. J. Mass Spectrom. 2002, 219, 203-232.

(69) Paizs, B.; Suhai, S. Mass Spectrom. Rev., in press.

(70) Case, D. A.; et al. Amber 96; University of California: San Francisco, 1999 
target ions can safely be explored by the applied computational strategy. For all ab initio and DFT calculations the Gaussian ${ }^{71}$ set of programs was used.

Throughout the paper the following structural/energetic denotations are used. The first characters represent either CS or SB structures. Because of the large number of different species obtained during the scan of the PES of $\mathrm{K}^{+}$tagged amino acids and peptides, we had to prune the field for detailed discussion. The selection was made primarily according to the energy of the species. Higher energy structures are described in detail only if they show a specific type of interaction which is not present in the energetically most favored species. With the notation of the various conformer families we follow the nomenclature introduced by Dunbar ${ }^{11}$ referring to the most important interactions between $\mathrm{K}^{+}$and functionalities of the investigated amino acids or peptides. For example, "CS N/O/ring" for $[\mathrm{Tyr}+\mathrm{K}]^{+}$denotes $\mathrm{K}^{+}$ binding to the amino nitrogen $(\mathrm{N}), \mathrm{COOH}$ carbonyl $(\mathrm{O})$, and the side chain phenyl ring (ring), respectively. For the peptides the amide oxygens are distinguished by numbering according to the corresponding amide bond. The Tyr and Phe side chain rings are noted by "Tring" and "Fring", respectively. The structures of the species explicitly mentioned in the paper are presented in the Supporting Information along with their electronic total energies computed at the B3LYP/6$31+\mathrm{G}(\mathrm{d}, \mathrm{p})$ level.

Note that the calculated spectra are all scaled by 0.96 , which is close to the recommended value by the NIST database $(0.9614)^{72}$ and is comparable to other literature values. ${ }^{23}$ Further, the calculated stick spectra are convoluted using a $20 \mathrm{~cm}^{-1}$ full-width at half-maximum (fwhm) Gaussian function.

\section{Results and Discussion}

(1) Amino Acids. (a) Assignment of CS versus SB Structure for $[\mathbf{T y r}+\mathbf{K}]^{+}$and $[\mathbf{P h e}+\mathbf{K}]^{+}$. The experimental infrared photodissociation spectra for $[\mathrm{Tyr}+\mathrm{K}]^{+}$(Figure 1A) and $[\mathrm{Phe}+\mathrm{K}]^{+}$(Figure 2A) are compared to theoretically calculated spectra in ascending energy (Figures $1 \mathrm{~B}-\mathrm{F}$ and $2 \mathrm{~B}-$ F). In a CS structure, the termini of the amino acid are neutral, whereas in a SB structure a proton is transferred from the $\mathrm{C}-$ to the N-terminus. For the lowest energy SB conformation, the potassium cation binds to the negatively charged carboxylate group (Figures $1 \mathrm{E}$ and $2 \mathrm{E}$ ), which involves a strong electrostatic interaction. ${ }^{14}$ The CS conformer N/O/ring (Figures 1B and 2B) is the lowest energy structure, in agreement with others, ${ }^{11,12,15}$ and is favored to the corresponding lowest energy SB conformer, $\mathrm{O} / \mathrm{O}$, by at least $\sim 10 \mathrm{~kJ} \mathrm{~mol}^{-1}$. The structures and energy gaps are comparable to the findings of Siu et al. for $[\mathrm{Phe}+\mathrm{Na}]^{+} .{ }^{12}$ However, their CS to SB energy gap is twice as large for [Phe $+\mathrm{K}]^{+}\left(20 \mathrm{~kJ} \mathrm{~mol}^{-1}{ }^{12}\right)$ than our $[\mathrm{Phe}+\mathrm{K}]^{+}$and $[\mathrm{Tyr}+\mathrm{K}]^{+}$ values. The computational work on $[\mathrm{Tyr}+\mathrm{K}]^{+}$by Dunbar suggests a $\pi$-bonded lowest energy SB structure at $28.0 \mathrm{~kJ} \mathrm{~mol}^{-1}$ relative energy. ${ }^{11}$ Our scans of the PESs of $[\mathrm{Phe}+\mathrm{K}]^{+}$and $[\mathrm{Tyr}+\mathrm{K}]^{+}$clearly indicate that, instead of $\mathrm{K}^{+} \pi$-bonding, the protonated amino terminus interacts with the side-chain ring for the most favored SB species. Given the accuracy of the calculation, a gap of $10 \mathrm{~kJ} \mathrm{~mol}^{-1}$ is too small to establish that only the CS structure is present and experimental evidence is required to support the results of the calculation.

The position of the $\mathrm{C}=\mathrm{O}$ stretching mode $(v(\mathrm{CO}))$ in amino acids is an accurate probe of whether the CS or SB structure is present, as shown by Kapota et al. for glycine and proline. ${ }^{23}$ This band is observed at $\sim 1750 \mathrm{~cm}^{-1}$ (see Figures $1 \mathrm{~A}$ and $2 \mathrm{~A}$ ).

(71) Frisch, M. J.; et al. Gaussian 98; Gaussian Inc.: Pittsburgh, PA, 1998. (72) NIST Chemistry Webbook, http://web-book.nist.gov/chemistry/.

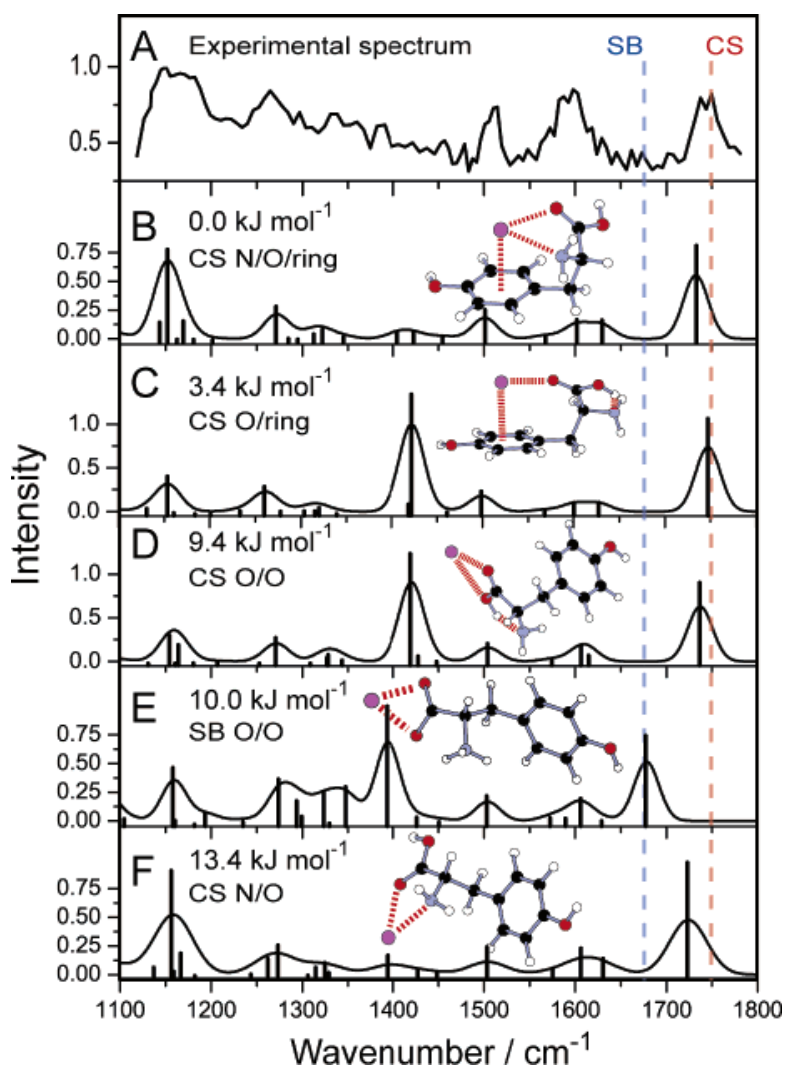

Figure 1. (A) Experimental infrared photodissociation spectrum of [Tyr $+\mathrm{K}]^{+}$. Calculated infrared spectra for the (B) N/O/ring bound charge solvation structure, (C) O/ring bound charge solvation structure, (D) O/O bound charge solvation structure, $(\mathrm{E}) \mathrm{O} / \mathrm{O}$ bound salt bridge structure, and (F) N/O bound charge solvation structure. The dashed lines indicate the band positions expected for SB $v_{\text {as }}\left(\mathrm{CO}_{2}^{-}\right)$and $\mathrm{CS}$ carboxylic acid $v(\mathrm{CO})$, respectively. Note that the maximum dissociation yield in the experimental spectrum is $\sim 30 \%$.

Note that this mode is also coupled to a $\mathrm{COH}$ bending mode of the carboxylic acid group, but that for the sake of simplicity modes are named according to the largest contribution only. A carboxylic acid $v(\mathrm{CO})$ can only be present in the CS structure. Note that all the spectra of the calculated CS structures have a band at this position. Conversely, the antisymmetric $v(\mathrm{CO})$ stretch of the $\mathrm{CO}_{2}^{-}$group, $v_{\text {as }}\left(\mathrm{CO}_{2}^{-}\right)$, which is present in the $\mathrm{SB}$ structure (Figures $1 \mathrm{E}$ and $2 \mathrm{E}$ ) is red-shifted to $\sim 1680 \mathrm{~cm}^{-1}$. No band is observed in the experimental spectra at this position, suggesting that all gas-phase $[\mathrm{Tyr}+\mathrm{K}]^{+}$and $[\mathrm{Phe}+\mathrm{K}]^{+}$ions at room temperature are in the CS structure. It may be further noted that the remainder of the experimental infrared spectra is also better fitted by the CS N/O/ring structure spectra (Figures $1 \mathrm{~B}$ and $2 \mathrm{~B}$ ) than by the $\mathrm{SB} \mathrm{O} / \mathrm{O}$ structures (Figures $1 \mathrm{E}$ and 2E).

(b) Assignment of $\mathrm{K}^{+}$Binding in $[\mathrm{Tyr}+\mathrm{K}]^{+}$and [Phe + $\mathbf{K}]^{+} \mathbf{C S}$ structures. Our scans of the PESs of $[\mathrm{Tyr}+\mathrm{K}]^{+}$and $[\mathrm{Phe}+\mathrm{K}]^{+}$resulted in a large number of individual conformers involving species similar to those reported previously for [Phe $+\mathrm{Na}]^{+} .{ }^{12}$ It is worth noting here that for $[\mathrm{Phe}+\mathrm{K}]^{+}$we located many new structures that energetically lie between the $\mathrm{N} / \mathrm{O} /$ ring and $\mathrm{O} / \mathrm{O} /$ ring species reported by Dunbar. ${ }^{11}$ Our structures have been analyzed and assigned into the N/O/ring, O/ring, O/O, and N/O families for which the energetically most favored structures are shown in Figures 1 and 2. The tridentate N/O/ ring structures are found to be lowest in energy (Figures $1 \mathrm{~B}$ and $2 \mathrm{~B}$ ), in agreement with what has previously been shown. ${ }^{11,12,15}$ 


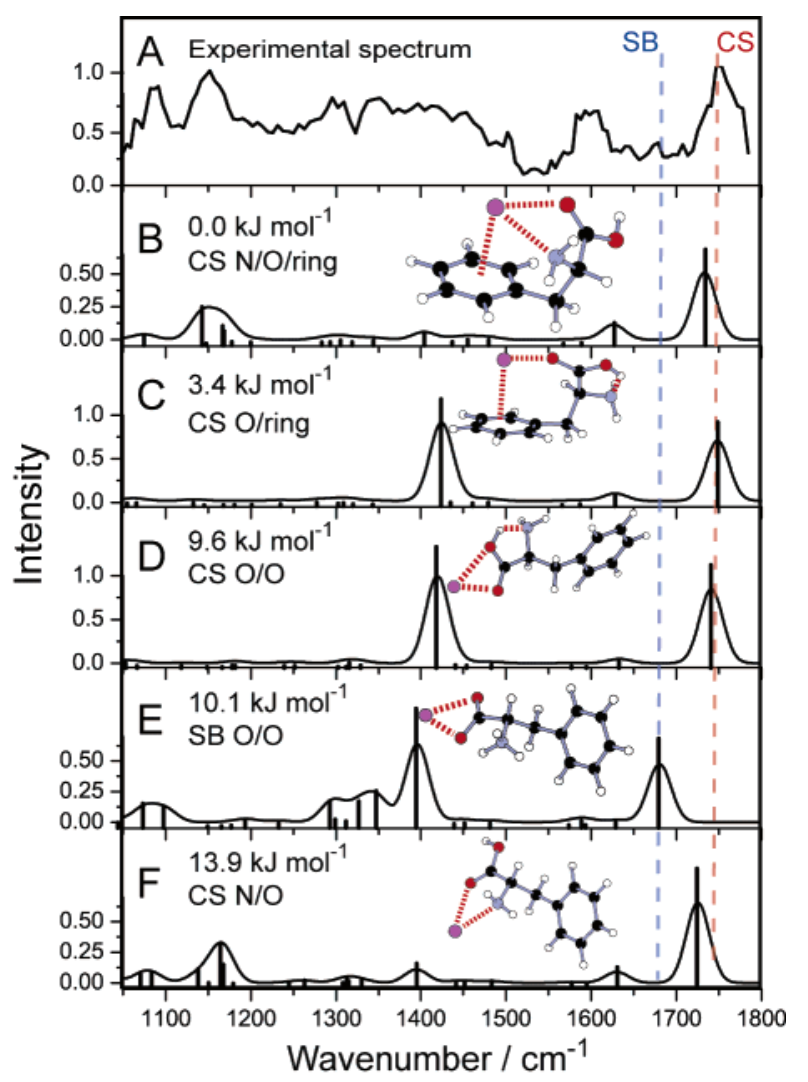

Figure 2. (A) Experimental infrared photodissociation spectrum of [Phe $+\mathrm{K}]^{+}$and calculated infrared spectra for the (B) N/O/ring bound charge solvation structure, (C) O/ring bound charge solvation structure, (D) O/O bound charge solvation structure, (E) $\mathrm{O} / \mathrm{O}$ bound salt bridge structure, and (F) N/O bound charge solvation structure. The dashed lines indicate the band positions expected for SB $v_{\text {as }}\left(\mathrm{CO}_{2}{ }^{-}\right)$and $\mathrm{CS}$ carboxylic acid $v(\mathrm{CO})$, respectively. Note that the maximum dissociation yield in the experimental spectrum is $50 \%$.

The second lowest energy structure shows $\mathrm{O} /$ ring $\mathrm{K}^{+}$binding (Figures $1 \mathrm{C}$ and $2 \mathrm{C}$ ), which is merely $3.4 \mathrm{~kJ} \mathrm{~mol}^{-1}$ higher in energy. In the next minimized conformation, $\mathrm{K}^{+}$is bound through the terminal $\mathrm{COOH}$ group (Figures 1D and 2D) and the highest energy conformation (Figures $1 \mathrm{~F}$ and $2 \mathrm{~F}$ ) shows $\mathrm{N} / \mathrm{O}$ binding. Note here that the $\mathrm{O} / \mathrm{O} /$ ring CS conformation is $\sim 17 \mathrm{~kJ} \mathrm{~mol}^{-1}$ higher in energy despite tridental binding than the lowest energy conformer for both amino acids and has hence not been included in the analysis.

For tyrosine the N/O/ring structure spectrum reproduces the high intensities of the spectral features at 1150 and $1265 \mathrm{~cm}^{-1}$, whereas the O/ring structure does not, and further, the very intense band at $1420 \mathrm{~cm}^{-1}$ (due to carboxylic acid $\mathrm{COH}$ bending) predicted for the O/ring structure (Figure 1C) is not observed in the experimental spectrum. Note that the high intensity of this mode is probably due to hydrogen bonding of the carboxylic acid hydrogen to the amino group. For phenylalanine the N/O/ring structure confirms the bands at 1087 and $1152 \mathrm{~cm}^{-1}$, whereas the O/ring structure does not. Here also, the very intense feature at $\sim 1420 \mathrm{~cm}^{-1}$ (Figure 2C) is not reflected in the experimental spectrum. Despite the small difference in energy between the lowest energy N/O/ring structure and the $\mathrm{O} /$ ring structure $\left(3.4 \mathrm{~kJ} \mathrm{~mol}^{-1}\right)$, the N/O/ring structure appears to be the major conformer observed under these experimental conditions. The calculated spectra for the N/O bound structures (Figures $1 \mathrm{~F}$ and $2 \mathrm{~F}$ ) are similar to the
Table 1. Summary of the Spectral Assignments of the Infrared Spectrum of $[\mathrm{Tyr}+\mathrm{K}]^{+}$based on the Calculated Spectrum for CS N/O/Ring (Figure 1B)

\begin{tabular}{ccrl}
\hline $\begin{array}{c}\text { expt } \\
\text { band } / \mathrm{cm}^{-1}\end{array}$ & $\begin{array}{c}\text { calcd } \\
\text { band } / \mathrm{cm}^{-1}\end{array}$ & $\begin{array}{c}\text { calcd intens/ } \\
\mathrm{km} \mathrm{mol}^{-1}\end{array}$ & \multicolumn{1}{c}{ assignment } \\
\hline 1150 & 1143 & 57 & carboxylic acid $\delta(\mathrm{COH})$ \\
& 1152 & 278 & Tyr $v(\mathrm{CC}), \delta(\mathrm{COH})$, and $\delta(\mathrm{CH})$ \\
1166 & 1169 & 61 & carboxylic acid $\delta(\mathrm{COH})$ \\
1265 & 1271 & 105 & Tyr $v(\mathrm{CC}), v(\mathrm{CO})$, and $\delta(\mathrm{CH})$ \\
1331 & 1322 & 35 & Tyr $v(\mathrm{CC})$ and $\delta(\mathrm{CH})$ \\
1510 & 1500 & 95 & Tyr $v(\mathrm{CC})$ and $\delta(\mathrm{CH})$ \\
1592 & 1601 & 65 & Tyr $v(\mathrm{CC})$ and $\delta(\mathrm{CH})$ \\
& 1629 & 63 & N $H_{2}$ in-plane scissoring \\
1744 & 1732 & 290 & carboxylic acid $v(\mathrm{CO})$ \\
\hline
\end{tabular}

${ }^{a}$ Note that some of the carboxylic acid $\delta(\mathrm{COH})$ modes are strongly delocalized.

Table 2. Summary of the Spectral Assignments of the Infrared Spectrum of $[\mathrm{Phe}+\mathrm{K}]^{+}$based on the Calculated Spectrum of CS N/O/Ring (Figure 2B) ${ }^{a}$

\begin{tabular}{cccl}
\hline $\begin{array}{c}\text { expt } \\
\text { band } / \mathrm{cm}^{-1}\end{array}$ & $\begin{array}{c}\text { calcd } \\
\text { band } / \mathrm{cm}^{-1}\end{array}$ & $\begin{array}{c}\text { calcd intens/ } \\
\mathrm{km} \mathrm{mol}^{-1}\end{array}$ & \multicolumn{1}{c}{ assignment } \\
\hline 1087 & 1075 & 23 & Phe $v(\mathrm{CC})$ and $\delta(\mathrm{CH})$ \\
1152 & 1142 & 113 & carboxylic acid $\delta(\mathrm{COH})$ \\
& 1167 & 54 & carboxylic acid $\delta(\mathrm{COH})$ \\
1397 & 1403 & 33 & carboxylic acid $\delta(\mathrm{COH})$ \\
1502 & 1479 & 12 & Phe $v(\mathrm{CC})$ and $\delta(\mathrm{CH})$ \\
1593 & 1588 & 2 & Phe $v(\mathrm{CC})$ and $\delta(\mathrm{CH})$ \\
& 1626 & 64 & $\mathrm{NH}_{2}$ in-plane scissoring \\
1753 & 1733 & 290 & carboxylic acid $v(\mathrm{CO})$ \\
\hline
\end{tabular}

${ }^{a}$ Note that some of the carboxylic acid $\delta(\mathrm{COH})$ modes are strongly delocalized.

$\mathrm{N} / \mathrm{O} /$ ring structure spectra (Figures $1 \mathrm{~B}$ and $2 \mathrm{~B}$ ) and can therefore not be distinguished spectroscopically. Nevertheless, the N/O conformers are higher in energy due to the absence of $\pi$-bonding and therefore unlikely to occur. It is known that the lack of $\pi$-bonding comes at a significant cost in energy, estimated here at $\sim 14 \mathrm{~kJ} \mathrm{~mol}^{-1}$ (comparable to $20 \mathrm{~kJ} \mathrm{~mol}^{-1}$ found by Dunbar ${ }^{11}$ ), which demonstrates that $\pi$-bonding is important in stabilizing the CS structure. ${ }^{12,37}$

(c) Spectral Interpretation for $[\mathrm{Tyr}+\mathrm{K}]^{+}$and $[\mathrm{Phe}+$ $\mathbf{K}]^{+}$. The interpretation of the experimental spectrum of [Tyr $+\mathrm{K}]^{+}$based on the N/O/ring structure (Figure 1B) is summarized in Table 1 . The band at $\sim 1750 \mathrm{~cm}^{-1}$ is due to the carboxylic acid $v(\mathrm{CO})$ as discussed before. While the chosen scaling factor of 0.96 seems appropriate to obtain a reasonable match between the bands in the calculated and experimental spectra for the whole spectrum, it may not be totally appropriate for the carboxylic acid $v(\mathrm{CO})$ (see Tables 1 and 2), for which a scaling factor of 0.97 would give a better agreement (thus calculated at $\sim 1750 \mathrm{~cm}^{-1}$ ). Note that it is known that in DFTcalculated spectra the optimum scaling factor can vary from mode to mode. ${ }^{73}$ Nonetheless, the same scaling factor $(0.96)$ is employed in the tables, whereas in the figures the carboxylic acid $v(\mathrm{CO})$ is indicated with a dashed line at $1750 \mathrm{~cm}^{-1}$. The side-chain modes of tyrosine clearly dominate the remainder of the spectrum; five bands are assigned to these side-chain modes, of which the bands at 1150, 1265, 1510, and $1592 \mathrm{~cm}^{-1}$ are clearly visible, whereas the band at $1331 \mathrm{~cm}^{-1}$ is less prominent. Some of these spectral bands are broadened (1150 and $1592 \mathrm{~cm}^{-1}$ ) due to an overlap with other modes (see Table 1). The calculated spectrum for the N/O/ring structure correctly

(73) Langhoff, S. R. J. Phys. Chem. 1996, 100, 2819-2841. 


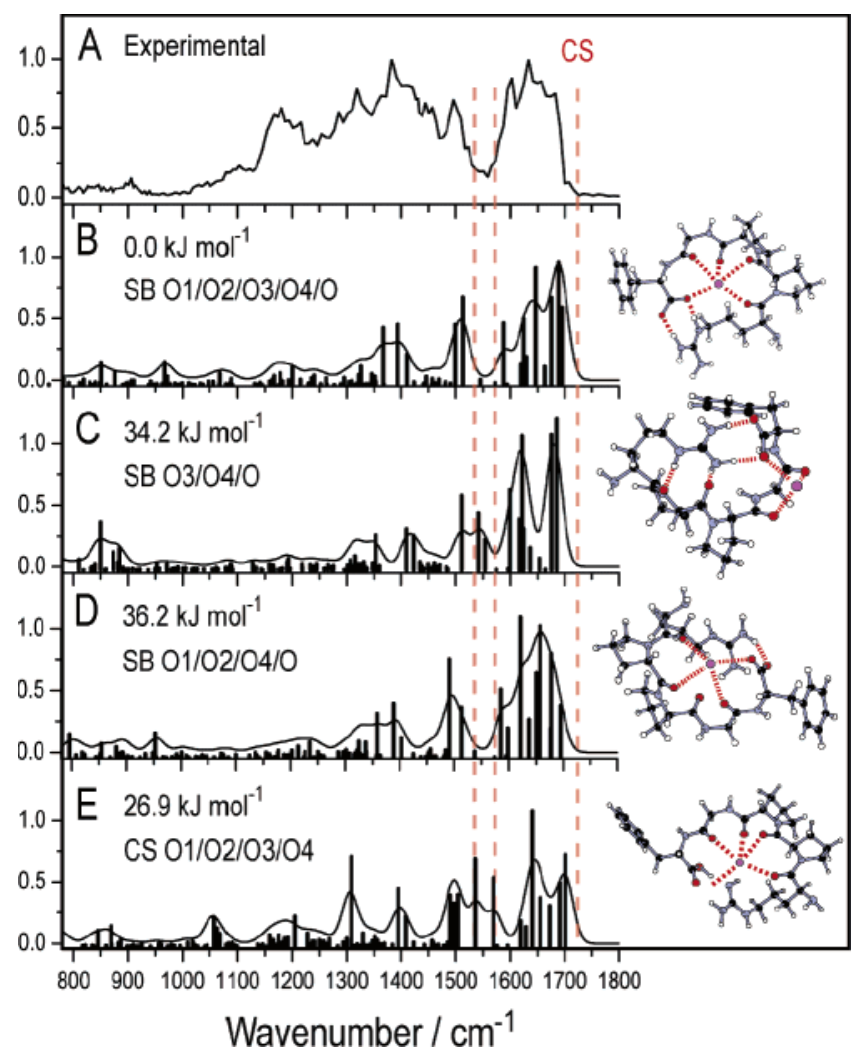

Figure 3. Bradykinin fragment 1-5 (Arg-Pro-Pro-Gly-Phe) tagged with $\mathrm{K}^{+}$. (A) Experimental spectrum. Calculated infrared spectra for (B) $\mathrm{SB}$ O1/ $\mathrm{O} 2 / \mathrm{O} 3 / \mathrm{O} 4 / \mathrm{O}$, (C) SB O3/O4/O, (D) SB O1/O2/O4/O, and (E) CS O1/O2/ $\mathrm{O} 3 / \mathrm{O} 4$. The dashed lines indicate the band positions expected for the CS proton-bound modes and carboxylic acid $v(\mathrm{CO})$. Note that the maximum fragmentation yield in the experimental spectrum is $4 \%$.

verifies the $1150 \mathrm{~cm}^{-1}$ band as the most intense peak in the spectrum, as well as the high intensity of the $1750 \mathrm{~cm}^{-1}$ band. The experimental bands at 1510 and $1592 \mathrm{~cm}^{-1}$ show good agreement between experiment and theory.

The interpretation of the experimental spectrum for [Phe + $\mathrm{K}]^{+}$is shown in Table 2, based on the calculated spectrum for the N/O/ring structure (Figure 2B). Not surprisingly, there are many similarities between the $[\mathrm{Tyr}+\mathrm{K}]^{+}$and $[\mathrm{Phe}+\mathrm{K}]^{+}$ spectra: The carboxylic acid $v(\mathrm{CO})$ appears at $1753 \mathrm{~cm}^{-1}$, and the spectral region between 1200 and $1450 \mathrm{~cm}^{-1}$ contains little structure. Therefore, the assignment of some of the bands in this region is more tentative.

The main difference with the $[\mathrm{Tyr}+\mathrm{K}]^{+}$spectrum is the activity of the side-chain modes. The side-chain modes of phenylalanine are seen at 1087, 1502, and $1593 \mathrm{~cm}^{-1}$ (Figure 2A); however, their intensities are not dominating the spectrum as much as is the case for the tyrosine side-chain modes. The calculated intensities for the phenylalanine side-chain modes (see Table 2) also confirm that they are lower than for the tyrosine side-chain modes (see Table 1). The feature at 1502 $\mathrm{cm}^{-1}$, in particular, is very weak. Naturally, the tyrosine $\mathrm{C}-\mathrm{O}$ stretching at $1265 \mathrm{~cm}^{-1}$ is not present in the phenylalanine spectrum, which in fact reconfirms the assignment of this band in the $[\mathrm{Tyr}+\mathrm{K}]^{+}$spectrum.

(2) Peptides. The infrared spectra of the pentapeptides bradykinin fragment 1-5 and [Leu]-enkephalin tagged with $\mathrm{K}^{+}$ are shown in Figures 3A and 4A. To our knowledge, these are the largest peptides that have so far been investigated using

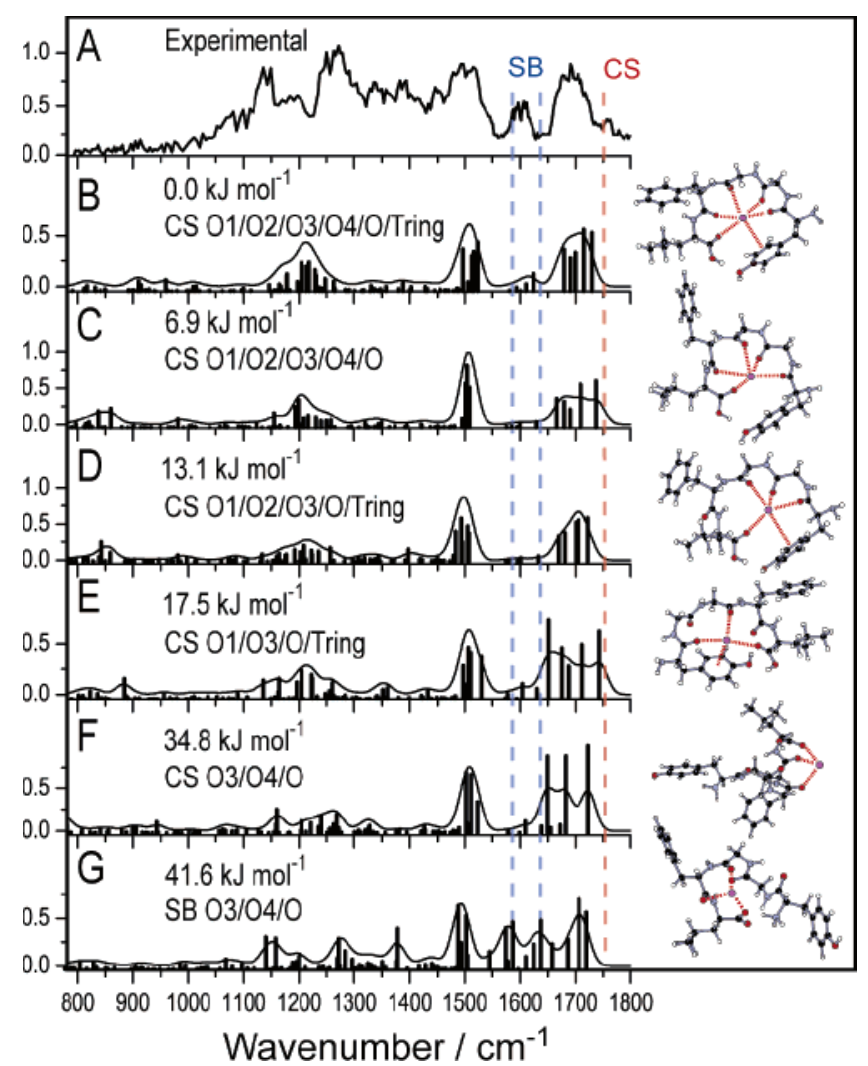

Figure 4. [Leu]-enkephalin (Tyr-Gly-Gly-Phe-Leu) tagged with $\mathrm{K}^{+}$. (A) Experimental spectrum. Calculated spectra and structures for (B) CS O1/ O2/O3/O4/O/Tring, (C) CS O1/O2/O3/O4/O, (D) CS O1/O2/O3/O/Tring, (E) CS O1/O3/O/Tring, (F) CS O3/O4/O, and (G) SB O3/O4/O. The dashed lines indicate the band positions expected for the SB proton-bound modes and $\mathrm{CS}$ carboxylic acid $v(\mathrm{CO})$, respectively. Note that the maximum fragmentation yield in the experimental spectrum is $17 \%$.

fingerprint infrared spectroscopy in the gas phase. Clearly, the spectra are both structured and very molecule-specific. Hereafter, we shall refer to bradykinin fragment $1-5$ tagged with $\mathrm{K}^{+}$as $[\mathrm{BK}+\mathrm{K}]^{+}$and to [Leu]-enkephalin tagged with $\mathrm{K}^{+}$as [enk + $\mathrm{K}]^{+}$for the sake of brevity.

(a) Assignment of CS or SB Structure for $[\mathbf{B K}+\mathbf{K}]^{+}$. The PES of $[\mathrm{BK}+\mathrm{K}]^{+}$has been carefully explored using the computational approach described above. We have investigated both SB (arginine side-chain protonated and C-terminal carboxylic acid deprotonated) and CS (neutral guanidine and $\mathrm{COOH}$ groups) forms. For the latter all five tautomers that could be derived for the neutral guanidine group have explicitly been considered. The modeling results have clearly shown that the energetically most favored SB structures are consistently lower in energy than the corresponding CS structures. For the lowest energy SB configuration (SB O1/O2/O3/O4/O, see Figures 3B and S1a (Supporting Information)) $\mathrm{K}^{+}$sits in the pocket of a looped structure, which is stabilized by five favorable $\mathrm{C}=\mathrm{O}$ dipole electrostatic interactions and a guanidine-carboxylate salt bridge. The lowest energy CS structure for $[\mathrm{BK}+\mathrm{K}]^{+}(\mathrm{CS}$ $\mathrm{O} 1 / \mathrm{O} 2 / \mathrm{O} 3 / \mathrm{O} 4$, Figures $3 \mathrm{E}$ and $\mathrm{S} 1 \mathrm{~b}$ (Supporting Information)) is $26.9 \mathrm{~kJ} \mathrm{~mol}^{-1}$ higher in energy. The CS O1/O2/O3/O4 structure is in fact very similar to the $\mathrm{SB} O 1 / \mathrm{O} 2 / \mathrm{O} 3 / \mathrm{O} 4 / \mathrm{O}$ structure, also displaying arginine side-chain hydrogen bonding to the $\mathrm{C}$-terminal carboxylic acid and the $\mathrm{K}^{+}$cation being held in pocket by four $\mathrm{C}=\mathrm{O}$ electrostatic interactions. Furthermore, $\mathrm{K}^{+}$sits above the plane of the $\mathrm{H}$-bonded guanidine and $\mathrm{COOH}$ groups benefiting from stabilization by their $\pi$ cloud. 
Therefore, the "coordination number" (i.e. number of electrostatic interactions between $\mathrm{K}^{+}$and electronegative sites of the peptide) for $\mathrm{K}^{+}$is five for the energetically most stable SB and CS species. According to chemical intuition and computational evidence, as the coordination number decreases, the corresponding structures become energetically less and less favored. For each structural family the lowest energy representative is shown; note that the range of structural energies within a particular family is typically $0-20 \mathrm{~kJ} \mathrm{~mol}^{-1}$ and that the diagnostic vibrations are almost identical. The relative energies of the energetically most favored representative structures for the 4-fold coordinated SB O1/O2/O4/O (Figures 3D and S1c (Supporting Information)) and the 3-fold coordinated SB O3/ O4/O families of structures (Figures 3C and S1d (Supporting Information)) are 36.2 and $34.2 \mathrm{~kJ} \mathrm{~mol}^{-1}$, respectively. The large energy gap between the 5-fold SB O1/O2/O3/O4/O and other coordination modes points again to the strength of potassium binding and the salt bridge experienced for the former. In general, stabilization of $\mathrm{K}^{+}$is more favored by the amide or carboxylic oxygens than by stabilization involving the $\mathrm{N}$ terminal amino or side-chain guanidine groups or the phenyl ring of the Phe side chain. For example, the most stable such structures which have $\pi$-cation interaction with the Phe side chain are at 47.2 and $70.6 \mathrm{~kJ} \mathrm{~mol}^{-1}$ for the $\mathrm{SB}$ (SB O2/O3/ O4/O/Fring, Figure S1e (Supporting Information)) and CS (O1/ O2/O3/O/Fring, Figure S1f (Supporting Information)) forms, respectively.

In the region of $1500-1600 \mathrm{~cm}^{-1}$ the $\mathrm{SB} 01 / \mathrm{O} 2 / \mathrm{O} 3 / \mathrm{O} 4 / \mathrm{O}$ structure calculated spectrum (Figure $3 \mathrm{~B}$ ) shows a much better agreement with the experimental spectrum (Figure 3A) than the CS O1/O2/O3/O4 structure (Figure 3E). The bands at 1540 and $1570 \mathrm{~cm}^{-1}$ in the CS structure spectrum which are not observed in the experimental spectrum are due to proton-bound modes between the $\mathrm{COOH}$ and guanidine groups. Further evidence for the SB structure configuration lies in the accurate fitting of the broad spectral envelope between 1600 and $1700 \mathrm{~cm}^{-1}$ by the SB 01/O2/O3/O4/O structure and the fact that no band appears above $1700 \mathrm{~cm}^{-1}$. The remainder of the experimental spectrum is also reasonably fitted using the SB O1/O2/O3/O4/O configuration, if one neglects the mismatch in intensities. This discrepancy may be due to a combination of inaccurate intensity predictions by the DFT method and nonlinearities in the IRMPD process. ${ }^{74}$

(b) Spectral Analysis of $[\mathbf{B K}+\mathbf{K}]^{+}$. A spectral analysis of the infrared spectrum of $[\mathrm{BK}+\mathrm{K}]^{+}$(Figure $3 \mathrm{~A}$ ) based on the calculated spectrum for structure SB (Figure $3 \mathrm{~B}$ ) is given in

(74) The discrepancy in intensities of the experimental IR-MPD spectra and calculated spectra can generally be ascribed to two main factors: (1) the DFT-calculated intensities are not correct and/or (2) the IR-MPD intensities are subject to nonlinear processes, which are not accounted for in the computed spectra. In the IR-MPD process, typically hundreds of photons are absorbed in a noncoherent fashion, which leads to an increase in the internal energy of the molecule. ${ }^{48}$ The anharmonicity of vibrational modes results in a red shift of the vibrational bands as the internal energy increases. In this study, the high IR-MPD intensities observed in the range between 1100 and $1450 \mathrm{~cm}^{-1}$ could be due the high density of bands in this region. For instance, we have shown previously that a higher than expected intensity is observed for a band on the red side of another band. ${ }^{64}$ By analogy, the high density of modes for these peptides (Figures 3 and 4) could boost the IR-MPD yield. At lower photon energies, say $<1100 \mathrm{~cm}^{-1}$, more photons are required to reach the dissociation threshold and hence a decrease in the IR-MPD yield may be comprehensible, despite the linear power correction applied. Note that the spectra of the amino acid complexes (Figures 1 and 2) do not have such a high density of modes as in the case of the peptides, and hence it is unclear if this hypothesis can explain the higher IR-MPD intensities of the amino acids in the $1200-1450 \mathrm{~cm}^{-1}$ region.
Table 3. Summary of the Spectral Assignments of the Infrared Spectrum of $[\mathrm{BK}+\mathrm{K}]^{+}$based on the $\mathrm{SB} 01 / \mathrm{O} 2 / \mathrm{O} 3 / \mathrm{O} 4 / \mathrm{O}$ Structure (Figure 3B)

\begin{tabular}{|c|c|c|c|}
\hline $\begin{array}{c}\text { expt } \\
\text { band } / \mathrm{cm}^{-1}\end{array}$ & $\begin{array}{c}\text { calcd } \\
\text { band } / \mathrm{cm}^{-1}\end{array}$ & $\begin{array}{l}\text { calcd intens/ } \\
\mathrm{km} \mathrm{mol}^{-1}\end{array}$ & assignment \\
\hline \multirow[t]{2}{*}{1180} & 1167 & 35 & Arg $\mathrm{NH}_{2}$ wag \\
\hline & 1179 & 46 & $\mathrm{Arg} \mathrm{CH}_{2}$ wag \\
\hline 1216 & 1201 & 65 & Gly $\{4\}$ and Phe $\{5\} v(\mathrm{C}(\mathrm{O}) \mathrm{N})$ \\
\hline \multirow[t]{2}{*}{1319} & 1323 & 39 & $v_{\mathrm{s}}\left(\mathrm{CO}_{2}^{-}\right)$ \\
\hline & 1327 & 71 & Pro $\mathrm{CH}_{2}$ wag \\
\hline \multirow[t]{3}{*}{1382} & 1369 & 217 & carboxylic acid $\delta(\mathrm{COH})$ \\
\hline & 1394 & 229 & Pro $\{3\} v(\mathrm{C}(\mathrm{O}) \mathrm{N})$ \\
\hline & 1412 & 116 & $\operatorname{Pro}\{2\} v(\mathrm{C}(\mathrm{O}) \mathrm{N})$ \\
\hline \multirow[t]{2}{*}{1496} & 1501 & 229 & amide II Gly $\{4\}$ \\
\hline & 1514 & 332 & amide II Phe $\{5\}$ \\
\hline \multirow[t]{9}{*}{$1603-1700$} & 1590 & 235 & $v_{\text {as }}\left(\mathrm{CO}_{2}^{-}\right)$ \\
\hline & 1622 & 81 & terminal $\mathrm{NH}_{2}$ scissoring \\
\hline & 1627 & 251 & $v_{\mathrm{s}}\left(\mathrm{CN}_{3} \mathrm{H}_{5}^{+}\right)$ \\
\hline & 1632 & 106 & amide $I \operatorname{Arg}\{1\}$ and $\operatorname{Pro}\{2\}$ in-phase \\
\hline & 1649 & 443 & amide $I \operatorname{Arg}\{1\}$ and $\operatorname{Pro}\{2\}$ out-of-phase \\
\hline & 1666 & 70 & $v_{\mathrm{s}}\left(\mathrm{CN}_{3} \mathrm{H}_{5}^{+}\right)$ \\
\hline & 1679 & 330 & amide I Pro $\{3\}$ and Gly $\{4\}$ in-phase \\
\hline & 1691 & 466 & $v_{\text {as }}\left(\mathrm{CN}_{3} \mathrm{H}_{5}^{+}\right)$ \\
\hline & 1698 & 293 & $\begin{array}{l}v_{\text {as }}\left(\mathrm{CN}_{3} \mathrm{H}_{5}+\right) \text { and amide I Pro }\{3\} \text { and } \\
\quad \text { Gly }\{4\}\end{array}$ \\
\hline
\end{tabular}

Table 3. The broad feature from 1600 to $1700 \mathrm{~cm}^{-1}$ in Figure $3 \mathrm{~A}$ is due to an overlap of $v_{\mathrm{as}}\left(\mathrm{CO}_{2}{ }^{-}\right)$, multiple strongly coupled amide I modes and symmetric as well as antisymmetric stretching of the guanidine group, $v_{\mathrm{s}}\left(\mathrm{CN}_{3} \mathrm{H}_{5}{ }^{+}\right)$and $v_{\text {as }}\left(\mathrm{CN}_{3} \mathrm{H}_{5}{ }^{+}\right)$. The peak falls off sharply at $1700 \mathrm{~cm}^{-1}$. While the relative intensity of the $1600-1700 \mathrm{~cm}^{-1}$ band in the calculated spectrum (Figure 3B) does not exactly match the experimental spectrum, the width of the band is reproduced, as well as the tail to the red.

The amide II band ( $\mathrm{N}-\mathrm{H}$ bending) is observed at $1496 \mathrm{~cm}^{-1}$ in agreement with calculation and is also very narrow (fwhm $=30 \mathrm{~cm}^{-1}$ ).

In general, the bands below $1500 \mathrm{~cm}^{-1}$ are more intense in the IR-MPD spectrum than in the calculated linear absorption spectra. ${ }^{74}$ Despite the discrepancy in intensities, the band positions are well-matched. The main peak in the spectrum at $1382 \mathrm{~cm}^{-1}$ is due to an overlap of $v_{\mathrm{s}}\left(\mathrm{CO}_{2}^{-}\right)$and the proline $\mathrm{C}(\mathrm{O})-\mathrm{N}$ stretches (amide III bands). The band at $1180 \mathrm{~cm}^{-1}$ is due to arginine side-chain modes: $\mathrm{CH}_{2}$ and $\mathrm{NH}_{2}$ wagging. With less certainty, the band at $1319 \mathrm{~cm}^{-1}$ is probably due to $\mathrm{CH}_{2}$ wagging of the proline and phenylalanine side chains.

(c) Assignment of CS or SB Structure for [enk $+\mathbf{K}]^{+}$. The peptide [Leu]-enkephalin does not have a very basic (proton-accepting) site as is the case for bradykinin fragment 1-5. Thus, the most energetically favored SB structure has a protonated $\mathrm{N}$-terminus and a deprotonated $\mathrm{C}$-terminus (Figures 4G and S1m (Supporting Information)). Both this SB and the $\mathrm{CS}$ (neutral $\mathrm{N}$-terminus and $\mathrm{COOH}$ groups) forms have been carefully investigated utilizing our computational strategy. The computational data suggest that the CS form of $[\mathrm{enk}+\mathrm{K}]^{+}$is energetically more favored than the SB form with an energy gap of $41.6 \mathrm{~kJ} \mathrm{~mol}^{-1}$. From the many investigated conformer families we present here representative structures from the CS O1/O2/O3/O4/O/Tring (Figures 4B and S1g (Supporting Information)), CS O1/O2/O3/O4/O (Figures 4C and S1h (Supporting Information), $\mathrm{CS} 01 / \mathrm{O} 2 / \mathrm{O} 3 / \mathrm{O} /$ Tring (Figures $4 \mathrm{D}$ and $\mathrm{S} 1 \mathrm{i}$ (Supporting Information)), CS O1/O3/O/Tring (Figures 4E and $\mathrm{S} 1 \mathrm{j}$ (Supporting Information)), and CS O3/O4/O (Figures 4F 
and S1k (Supporting Information)) families showing 6-, 5-, 5-, 4-, and 3-fold coordination of $\mathrm{K}^{+}$at $0.0,6.9,13.1,17.5$, and $34.8 \mathrm{~kJ} \mathrm{~mol}^{-1}$ relative energies. As expected, the most stable CS O1/O2/O3/O4/O/Tring species show high coordination of $\mathrm{K}^{+}$leading to a very compact geometry stabilized by five carbonyl $\mathrm{O} \cdots \mathrm{K}^{+}$and the Tring $\cdots \mathrm{K}^{+} \pi$ interactions. For [enk $+\mathrm{K}]^{+}$there is a gradual increase in energy upon a decrease in $\mathrm{K}^{+}$coordination. Conversely, for $[\mathrm{BK}+\mathrm{K}]^{+}$there is a large energy gap between the 5-fold SB O1/O2/O3/O4/O structure and the lower coordinated structures.

It is worth noting here that for many of the energetically most favored species, the Tyr side chain is involved in the chelation of $\mathrm{K}^{+}$, pointing to the importance of cation $-\pi$ interactions. On the other hand, the Phe side chain takes part in the chelation of $\mathrm{K}^{+}$only in relatively high-energy structures such as CS O1/ O4/Tring/Fring (Figure S11 (Supporting Information), 30.6 kJ $\left.\mathrm{mol}^{-1}\right)$. From looking at the calculated structures it is apparent that Phe is sterically hindered to form such an interaction, whereas Tyr is in a favorable position.

The energetically most favored SB species, SB O3/O4/O (Figures 4G and S1m (Supporting Information)) at $41.6 \mathrm{~kJ}$ $\mathrm{mol}^{-1}$, is stabilized by 3 -fold chelation of $\mathrm{K}^{+}$and the $\mathrm{NH}_{3}{ }^{+} \cdot \cdots \mathrm{COO}^{-}$salt bridge. While we have found some SB structures with 4-fold chelation, it is generally found that the $\mathrm{SB}$ species of $[\mathrm{enk}+\mathrm{K}]^{+}$show less efficient stabilization of $\mathrm{K}^{+}$than the corresponding CS structures. Furthermore, neither the Tyr nor the Phe side chain ring is involved in chelation of $\mathrm{K}^{+}$for the energetically most favored SB species of [enk + $\mathrm{K}]^{+}$.

By comparing the theoretical spectra to the experimental spectrum in Figure 4A, it is clear that none of the calculated spectra fit particularly well over the whole frequency range shown. Nevertheless, the weak, though clearly present, band at $1750 \mathrm{~cm}^{-1}$ indicates the presence of a terminal $\mathrm{COOH}$, and hence at least a reasonable fraction of the $[\mathrm{enk}+\mathrm{K}]^{+}$complexes must be in the CS structure. Given that merely one $\mathrm{COOH}$ group is present, compared to four amide carbonyls, the intensity of a carboxylic acid $v(\mathrm{CO})$ becomes relatively weaker for peptides than for amino acids. Further, the diagnostically most important frequency range for the study of CS and SB between 1450 and $1800 \mathrm{~cm}^{-1}$ is reasonably well replicated with the theoretical spectrum belonging to the lowest energy CS structure (Figure 4B). Since the SB diagnostically important proton-bound modes could in principle overlap with the prominent $1600 \mathrm{~cm}^{-1}$ band, we cannot completely exclude the SB structure. However, given the absence of a high basicity site in [Leu]-enkephalin and the results from the calculations, it seems reasonable that the CS structure should be greatly favored.

(d) Spectral Analysis of $[\mathbf{e n k}+\mathbf{K}]^{+}$. Table 4 presents the spectral interpretation of the $[\mathrm{enk}+\mathrm{K}]^{+}$spectrum (shown in Figure 4A) based on structure CS O1/O2/O3/O4/O/Tring (Figure 4B). As discussed, the band at $1753 \mathrm{~cm}^{-1}$ is due to the carboxylic acid $v(\mathrm{CO})$. The position of this band is observed at the same frequency as is the case for $[\mathrm{Phe}+\mathrm{K}]^{+}$and $[\mathrm{Tyr}+$ $\mathrm{K}]^{+}$(Figure 5), evidencing the presence of the CS structure.

The $1690 \mathrm{~cm}^{-1}$ band is due to an overlap of the different amide I modes. These modes are strongly coupled, displaying either in-phase or out-of-phase behavior. The spectral resolution, determined by the IR-MPD process and the line density rather
Table 4. Summary of the Spectral Assignments of the Infrared Spectrum of $[\mathrm{Enk}+\mathrm{K}]^{+}$based on the CS O1/O2/O3/O4/O/Tring Structure (Figure 4B) ${ }^{a}$

\begin{tabular}{ccrl}
\hline $\begin{array}{c}\text { expt } \\
\text { band/cm }\end{array}$ & $\begin{array}{c}\text { calcd } \\
\text { band/cm }\end{array}$ & $\begin{array}{c}\text { calcd intens/ } \\
\mathrm{km} \mathrm{mol}^{-1}\end{array}$ & \multicolumn{1}{c}{ assignment } \\
\hline 1140 & 1174 & 126 & Tyr $v(\mathrm{CC}), \delta(\mathrm{COH})$, and $\delta(\mathrm{CH})$ \\
1200 & 1190 & 169 & carboxylic acid $\delta(\mathrm{COH})$ \\
& 1198 & 176 & $v(\mathrm{C}(\mathrm{O}) \mathrm{N})$ Gly $\{2\}$ \\
1260 & 1232 & 95 & Tyr $v(\mathrm{CC}), v(\mathrm{COH})$, and $\delta(\mathrm{CH})$ \\
& 1253 & 62 & backbone $\mathrm{CH}_{2}$ wag \\
1380 & 1389 & 46 & carboxylic acid $\delta(\mathrm{COH})$ \\
1500 & 1500 & 62 & Tyr $v(\mathrm{CC})$ and $\delta(\mathrm{CH})$ \\
& 1503 & 233 & amide II Gly $\{3\}$ \\
& 1507 & 173 & amide II Phe $\{4\}$ \\
& 1513 & 163 & amide II Gly $\{2\}$ \\
1600 & 1517 & 329 & amide II Leu $\{5\}$ \\
& 1604 & 32 & Tyr $v(\mathrm{CC})$ and $\delta(\mathrm{CH})$ \\
1690 & 1631 & 56 & terminal NH 2 scissoring \\
& 1668 & 243 & amide I Gly $\{3\}$ and Leu $\{5\}$ in-phase \\
& 1675 & 225 & amide I Tyr $\{1\}$ and Gly $\{2\}$ out-of-phase \\
& 1691 & 197 & amide I Tyr $\{1\}$ and Gly $\{2\}$ in-phase \\
1753 & 1716 & 302 & amide I Tyr $\{1\}$ and Gly $\{2,3\}$ in-phase \\
& 1733 & 277 & carboxylic acid $v(\mathrm{CO})$ \\
\hline
\end{tabular}

${ }^{a}$ Note that the amide I modes are strongly coupled.

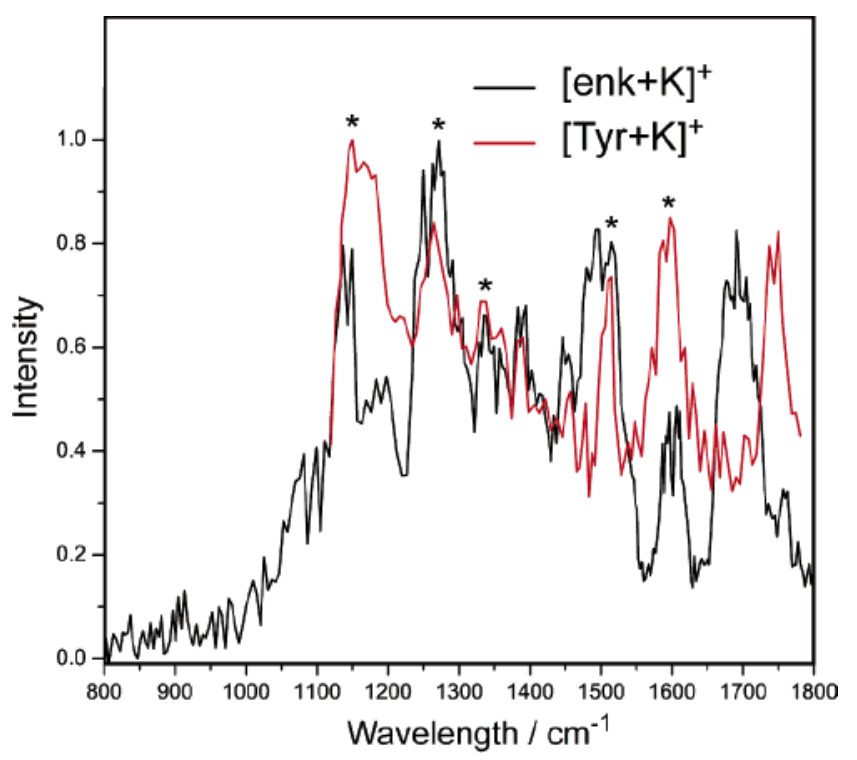

Figure 5. Overlayed photodissociation spectra for $[\mathrm{enk}+\mathrm{K}]^{+}$and $[\mathrm{Tyr}$ $+\mathrm{K}]^{+}$, showing appearance of tyrosine side-chain bands (marked with asterisks $(*))$ in the $[\mathrm{enk}+\mathrm{K}]^{+}$spectrum.

than by the laser bandwidth, is insufficient to differentiate between the different amide I modes.

The amide II mode is again found at $1500 \mathrm{~cm}^{-1}$. The width of the band is much wider than is the case for $[\mathrm{BK}+\mathrm{K}]^{+}$, and a double peak feature seems to be present. The second band appears to be due to a tyrosine side-chain mode.

In general, the tyrosine side-chain modes leave a very strong imprint on the $[\mathrm{enk}+\mathrm{K}]^{+}$spectrum. All the side-chain bands of tyrosine that are observed in the $[\mathrm{Tyr}+\mathrm{K}]^{+}$spectrum $(1150$, 1265, 1333, 1510, and $1592 \mathrm{~cm}^{-1}$; see Table 1) are also observed in the $[\mathrm{enk}+\mathrm{K}]^{+}$spectrum 1140, 1260, 1335, 1500, and $1600 \mathrm{~cm}^{-1}$ (see Table 4), with minor frequency shifts. This can clearly be seen when the two spectra are overlayed, as is done in Figure 5. The calculated frequencies for these modes in the structure CS O1/O2/O3/O4/O/Tring of [enk + K $]^{+}$(Figure 4B) match the observed band positions reasonably well; however, their intensities appear to be underestimated. Solution- 
phase data on side-chain infrared activities also confirm the high absorption intensities of the tyrosine side-chain modes and their band positions. ${ }^{75}$

[Leu]-enkephalin is known to have a very flexible backbone, and this renders a theoretical treatment of this molecule particularly challenging. Computational results on capped [Leu]enkephalin have shown that many conformers lie in close proximity energetically. ${ }^{59}$ These findings also demonstrated that the relative intensities of the infrared bands change significantly as a function of the structure, which seems in agreement with our findings. At room temperature the structure of $[\mathrm{enk}+\mathrm{K}]^{+}$ may be fairly dynamic, ${ }^{76}$ resulting in a less tightly bound $\mathrm{K}^{+}$ (than in the case of $[\mathrm{BK}+\mathrm{K}]^{+}$), which is supported by the higher fragmentation yield $(17 \%)$ of $[\mathrm{enk}+\mathrm{K}]^{+}$compared to $[\mathrm{BK}+\mathrm{K}]^{+}(4 \%)$ under similar experimental conditions.

\section{Conclusions}

Infrared spectroscopy of $[\mathrm{Phe}+\mathrm{K}]^{+}$and $[\mathrm{Tyr}+\mathrm{K}]^{+}$assisted with quantum chemical calculations has demonstrated that binding to $\mathrm{K}^{+}$does not favor a SB structure in the gas phase. Of the CS structures the tridentate N/O/ring bound conformation is most favored. On the basis of spectroscopic evidence alone, a non-ring bound structure would also be possible, but this is disfavored energetically.

Modeling of $[\mathrm{BK}+\mathrm{K}]^{+}$shows that the SB structure of this complex is much favored energetically, which is confirmed by the experimental infrared spectrum. The SB stabilization between the protonated guanidine group and the deprotonated C-terminus favors a looped head-to-tail structure, thereby forming a pocket in which $\mathrm{K}^{+}$is held through electrostatic interactions with the $\mathrm{C}=\mathrm{O}$ groups.

Calculations for $[\mathrm{enk}+\mathrm{K}]^{+}$clearly show that the CS structure is favored to the SB structure. The weak band observed at 1750 $\mathrm{cm}^{-1}$ confirms that at least some fraction of $[\mathrm{enk}+\mathrm{K}]^{+}$ complexes exist in the CS structure. The presence of the SB structure cannot be excluded for $[\mathrm{enk}+\mathrm{K}]^{+}$, due to the prominence of the band at $1600 \mathrm{~cm}^{-1}$, assigned to a tyrosine side-chain mode, which may overlap with diagnostic SB modes.

Whereas for $[\mathrm{enk}+\mathrm{K}]^{+}$there is a gradual increase in energy upon lower coordination of $\mathrm{K}^{+}$, for $[\mathrm{BK}+\mathrm{K}]^{+}$the $\mathrm{SB} \mathrm{O} 1 /$ $\mathrm{O} 2 / \mathrm{O} 3 / \mathrm{O} 4 / \mathrm{O} 5$-fold coordinated structure is much favored to lower coordinated structures. This supports the view that this structure is particularly stable and also helps rationalize the low fragmentation yield of $[\mathrm{BK}+\mathrm{K}]^{+}(4 \%)$ compared to [enk + $\mathrm{K}^{+}(17 \%)$ under very similar experimental conditions. The presence of two proline residues constrains the conformational

(75) Barth, A. Prog. Biophys. Mol. Biol. 2000, 74, 141-173.

(76) Kamihira, M.; Naito, A.; Tuzi, S.; Saito, H. J. Phys. Chem. A 1999, 103, $3356-3363$ freedom of the bradykinin fragment 1-5 peptide, thereby lending further credence to a rigid and therefore stable structure. In contrast to [Leu]-enkephalin, bradykinin fragment 1-5 appears to have the ideal size to form a binding pocket for $\mathrm{K}^{+}$in the zwitterionic form due to the arginine side chain.

The high intensities of the tyrosine side-chain modes in the $[\mathrm{enk}+\mathrm{K}]^{+}$spectrum are intriguing, and more theoretical work will be required to address this issue in terms of DFT predicted intensities.

In conclusion, it has been shown that valuable structural information on $\mathrm{K}^{+}$binding to amino acids and peptides can be gained by comparing their infrared gas-phase spectra to DFT calculations. The spectral region between 1500 and $1800 \mathrm{~cm}^{-1}$ is strongly indicative of the presence of a CS or SB structure. The region below $1500 \mathrm{~cm}^{-1}$, while yielding less structural information, nevertheless contains important information on the side-chain modes. The technique of alkali metal tagging in conjunction with photodissociation spectroscopy is a highly sensitive technique, which can readily be applied to larger peptides and even proteins ${ }^{77}$ in the gas phase. Further, electrospray ionization is capable of producing a wide range of interesting noncovalently bound biomolecular complexes (e.g. hydrated peptides, protein-ligand complexes) that can be investigated by infrared photofragment spectroscopy in the gasphase.

Acknowledgment. This work is part of the research program of FOM, which is financially supported by the "Nederlandse Organisatie voor Wetenschappelijk Onderzoek" (NWO). The skillful assistance by the FELIX staff is gratefully acknowledged. B.P. and S.S. are indebted to the Deutsche Forschungsgemeinschaft (Grant SU 244/3-1) for financial support. L.C.S. gratefully acknowledges the Royal Society for their support under the University Research Fellowship scheme and Corpus Christi College, Oxford, for a Research Fellowship. Construction and shipping of the instrument was made possible with funding from the National High Field FT-ICR Facility (Grant No. CHE9909502) at the National High Magnetic Field Laboratory, Tallahassee, FL. We thank Professors John R. Eyler and Alan G. Marshall for their collaboration with the FT-ICR project.

Supporting Information Available: Selected DFT optimized structures, as well as energetics (in hartrees), for potassium tagged bradykinin fragment $1-5$ and [Leu]-enkephalin and complete refs 70 and 71 (PDF). This material is available free of charge via the Internet at http://pubs.acs.org.

\section{JA050858U}

(77) Oomens, J.; Polfer, N.; Moore, D. T.; van der Meer, A. F. G.; Marshall, A. G.; Eyler, J. R.; Meijer, G.; von Helden, G. Phys. Chem. Chem. Phys. 2005, 7, 1345-1348. 